\title{
Experimental study on bond performance between GFRP bars and concrete
}

\author{
Fu Decheng ${ }^{1,2, *}$, Wang $\mathrm{Bo}^{3}$ \\ ${ }^{1}$ College of Civil Engineering, Changchun Institute of Technology, Changchun, China \\ ${ }^{2}$ Laboratory of Earthquake Resistance and Disaster Reduction for Civil Engineering of Jilin Province, Changchun, China \\ ${ }^{3}$ School of Civil Engineering, Jilin Jianzhu University, Changchun, China
}

\begin{abstract}
Based on 27 bonding test of pull-out specimens, the bonding performance between GFRP and concrete was studied systematically. The bond failure between concrete and GFRP includes four stages: microslip stage, linear slip stage, nonlinear slip stage and bond failure stage. The experiment shows that there is no significant correlation between concrete strength and bond strength, bond strength increases with the bond length and decreases with the increase of GFRP reinforcement diameter.
\end{abstract}

\section{Introduction}

Steel bar has an absolute advantage in reinforced concrete, the steel bar in concrete is protected by alkaline concrete, which makes the structure have properties of corrosion resistance and fire resistance.

However, the protection is not absolutely effective. Under the action of humidity, temperature, carbon dioxide and chloride ion, the alkalinity of concrete is gradually reduced, the passive film of steel bar is damaged, and the reinforcement begins to corrode, and the structural reliability is reduced ${ }^{[1]}$.

FRP reinforcement is a composite material with highperformance fiber as reinforcement and synthetic resin as base material, which is formed after die extrusion and surface treatment. It is a good substitute for reinforcement. Because of its excellent corrosion resistance and mechanical properties, it has gradually become a research hot spot ${ }^{[2-3]}$.

The bond force between FRP bars and concrete is the basis of collaborative work. The research on the bond failure and the bond mechanism between FRP bars and concrete is the basis of the research on FRP reinforced concrete structure ${ }^{[4-6]}$.

\section{Experiment design}

\subsection{Specimen making and loading device}

According to Standard for test method of mechanical properties on ordinary concrete ${ }^{[7]}$, a total of 27 pull-out test specimens were designed for the experiment, the size of the test pieces is shown in Fig.1. The concrete strength was classified as C20, C30 and C40. The GFRP bars used in the test were twined by fiber bundle and bonded with sand on surface. The diameter of GFRP bars is $9.53 \mathrm{~mm}, 12.7 \mathrm{~mm}$ and $15.88 \mathrm{~mm}$. The embedded depth of GFRP bars is $5 \mathrm{~d}, 10 \mathrm{~d}$ and $20 \mathrm{~d}$ respectively, where $\mathrm{d}$ is the diameter.

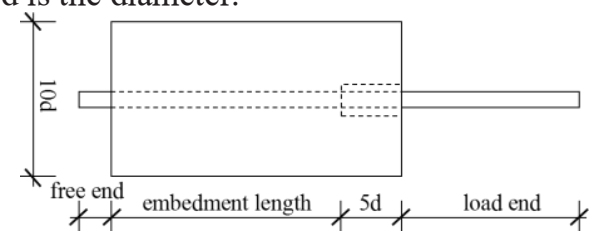

Fig. 1. Pull-out testing specimen.

Elastic modulus of bar $E=40.8 \times 10^{3} \mathrm{MPa}$,Section area of $9.53 \mathrm{~mm}$ diameter bar $A_{\mathrm{s}}=84.32 \mathrm{~mm}^{2}$, tensile strength $f_{\mathrm{y}}=760 \mathrm{MPa}$. Section area of $12.7 \mathrm{~mm}$ diameter bar $A_{\mathrm{s}}=144.85 \mathrm{~mm}^{2}$, tensile strength $f_{\mathrm{y}}=690 \mathrm{MPa}$. Section area of $15.88 \mathrm{~mm}$ diameter bar $A_{\mathrm{s}}=217.56 \mathrm{~mm}^{2}$, tensile strength $f_{\mathrm{y}}=655 \mathrm{MPa}$.Concrete cube compression strength test values of $\mathrm{C} 20$ is $f_{\text {cu }}=33.5 \mathrm{MPa}, \mathrm{C} 30$ is $f_{\text {cu }}=42.4 \mathrm{MPa}, \mathrm{C} 40$ is $f_{\text {cu }}=48.4 \mathrm{MPa}$.

In this experiment, we use an electronic steel strand tensile machine as loading device, and a hanging basket is designed according to Standard for test method of mechanical properties on ordinary concrete. The cube test specimen is placed in the hanging basket, the hanging basket is fixed at the upper end of the loading device, the GFRP reinforcement is clamped to exert tension, and the load is controlled by force. The loading device is shown in Fig. 2.

\footnotetext{
* Corresponding author: fudecheng@126.com
} 


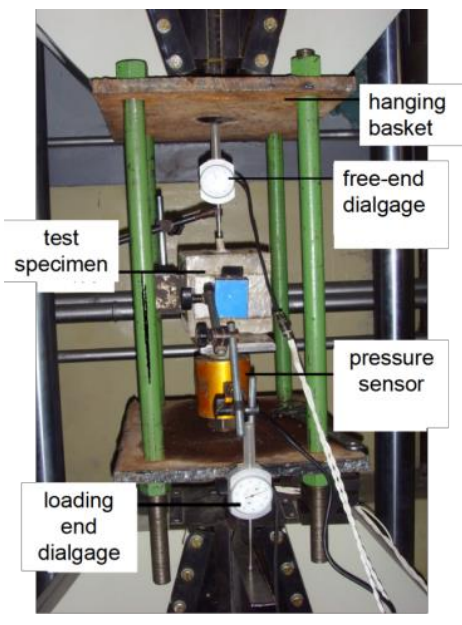

Fig. 2. Test setup of pull out specimen.

\subsection{Test loading process}

First, clamp the upper end of the basket with the loading device, then set the test specimen and the pressure sensor into the basket, clamp the GFRP bar with the jaw of the loading device, and two aluminum sheets $(22 \mathrm{~mm}$ long and $1 \mathrm{~mm}$ thick) are used at the loading end of the GFRP bar to prevent the local damagement caused by the clamp. Then set the displacement meter at free end and loading end, connect the displacement meter and pressure sensor with the data recording instrument, and collect the data per 2 seconds. The loading speed is $0.08 \mathrm{kN} / \mathrm{s}$.

\section{Failure mode of test specimen}

Among the 27 specimens, there are 9 specimens with GFRP bar pull-out failure, 11 specimens with splitting failure and 7 specimens with GFRP bar broken failure. When the embedded depth is $5 \mathrm{~d}$, the failure mode of the specimens is pull-out failure, when the embedded depth increases to $10 \mathrm{~d}$, the specimens begin to appear splitting failure. When the embedded depth is $20 \mathrm{~d}$, most of the failure mode becomes GFRP bar broken failure.

(1) GFRP bar pull-out failure: before the bar pull out, the slip of free end and loading end increases rapidly. When the bar was pulled out, the free end was retracted into the concrete. There were obvious friction marks on the bonding part of GFRP bar and concrete, and the bonding part of the reinforcement surface was abraded off. The friction between ribs was serious. The concrete has powdery debris at the surface of bond part. Fig.3 shows the typical failure mode of GFRP reinforcement.

(2) Splitting failure of test specimen: before splitting failure happened, the slip of free end and loading end increased rapidly, the concrete cracked suddenly,. The concrete cracks are all in the center of the section. Generally, a main crack went through the whole test specimen, and the cracks developed from the free end to the loading end. There were obvious friction marks between GFRP ribs, the bonded sand on the surface of GFRP is seriously worn, and the surface near the loading end is peeling off. Fig.4 shows the typical splitting failure mode of the specimen.

(3) fracture failure of GFRP bar: before fracture failure of the bar, the slip of the loading end increases rapidly, while the free end did not produce relative slip or the relative slip were slightly. When the specimen were damaged, at loading end, the fiber rib of the bar broke and the bar cracked into bundles. There were no cracks in the concrete. there were serious friction traces on the surface of the GFRP bar at loading end, and the friction traces were shallow near the free end. Fig.5 shows the typical fracture failure mode of GFRP bar.

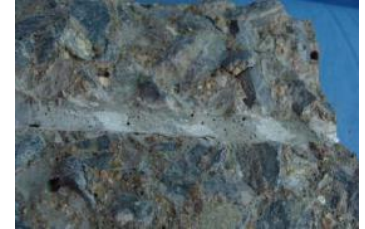

(a)Concrete failure surface

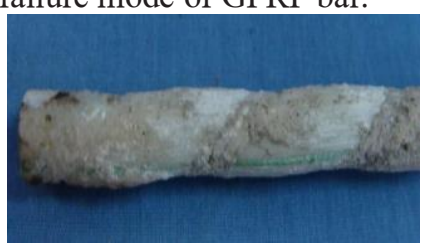

(b)Bond end of the bar
Fig. 3. Pull-out failure mode.

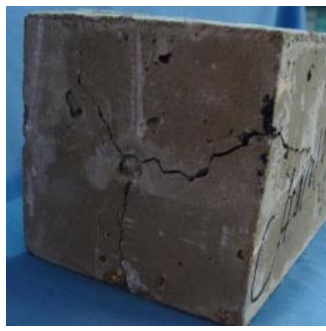

Fig. 4. Split failure mode.

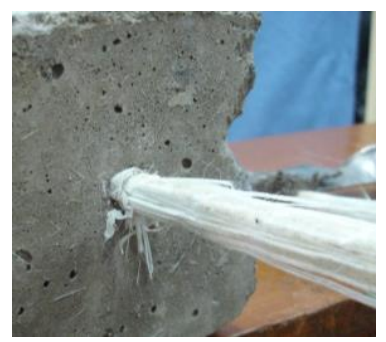

Fig. 5. Split failure mode.

\section{Analysis of test results}

\subsection{Analysis of bond-slip curve}

The typical average bond stress-slip curve ( $\tau$ - $s$ curve) of specimens with a bond length of $5 \mathrm{~d}$ is shown in Fig.6. Cite an example, C20135d indicates that the concrete strength grade is $\mathrm{C} 20$, the nominal diameter of GFRP reinforcement is $13 \mathrm{~mm}$, and the bond length is 5 times of the diameter.

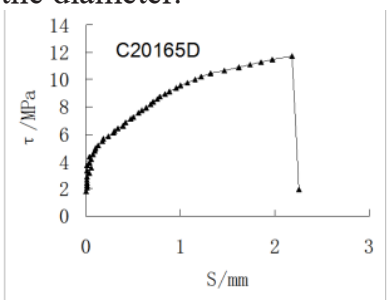

(a) Specimen C20165D

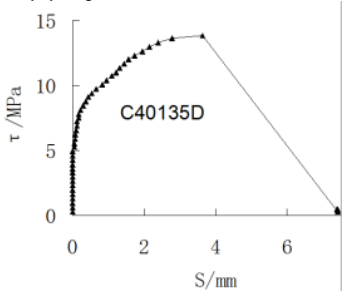

(c) Specimen C40135D

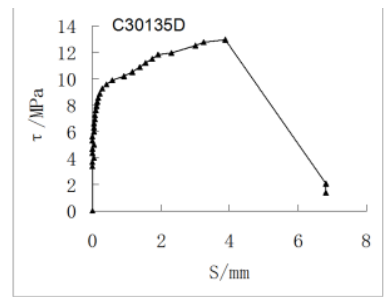

(b) Specimen C30135D

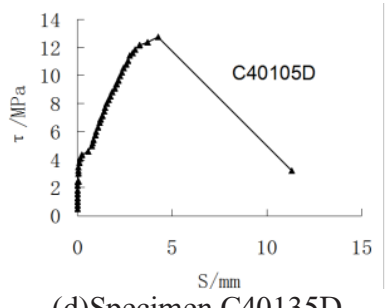

(d)Specimen C40135D
Fig. 6. Bond-slip relationship of GFRP bars. 
From Fig.6, we can see that the stress process of bond test mainly includes the following stages:

(1) Microslip stage: the microslip stage occurs at the initial stage of loading. The $\tau$-s curve shows that the increase of bond stress and the increase of slip is smaller, and the curve develops vertically along the longitudinal axis. At this time, the adhesive force is the most important part of the bond force.

(2) Linear slip stage: with the increase of load, the specimen enters the linear slip stage. In this stage, the slope of the curve is lower than that of microslip stage, and keeps a stable value. At this time, $\tau$-s curve is linear. The bond force is mainly composed of friction force and mechanical bite force between rib and concrete.

(3) Nonlinear slip stage: the load continues to increase, the slip growth rate further accelerates, and the $\tau$-s curve begins to be nonlinear. When it is close to the maximum bond stress, the curve shows a trend of horizontal development, and the slip increases sharply. In this stage, the mechanical bite force between GFRP rib and concrete is the main factor.

(4) Bond failure stage: when the bond stress reaches the maximum bond stress, the bar will been pull out or the concrete split, the slip increase suddenly, but the load decrease rapidly. $\tau$-s curve will decrease linearly. It can be seen from the date that when the splitting failure (C40135d and C20135d) occurs, the descending part of the curve is closer to the transverse axis, and the bearing capacity of the specimen is completely disappear. For the split specimen, when the load increases gradually, the compression force of GFRP rib on the surrounding concrete increases gradually, and the circumferential tensile stress produced by its radial component force in the concrete increases gradually, and the internal crack develops continuously. When the load is close to the ultimate load, the crack develops to the concrete surface, extending from the loading end to the free end. When the ultimate load is reached, the specimen suddenly splits into two pieces.

\subsection{Analysis of main influencing factors of bond strength}

(1) Concrete strength: the test results show that the bond strength $\tau_{\mathrm{u}}$ has no obvious correlation with the compression strength of concrete, because the bond failure is not only the concrete splitting failure, but also the GFRP bar fracture and pull-out failure.

(2) Bond length: for specimens with the same diameter of GFRP bar and concrete compression strength under the same failure mode, the typical relationship between bond length and bond strength is shown in Fig.7. It can be seen from Fig.7 that the bond length has a great influence on the bond strength under the same failure mode. With the same diameter, the bond strength of GFRP bar decreases with the increase of bond length. For the $13 \mathrm{~mm}$ diameter GFRP bar in C20 concrete, when the embedded length changes from $5 \mathrm{~d}$ to $10 \mathrm{~d}$, the bond strength decreases by $11.04 \%$; for the $16 \mathrm{~mm}$ diameter GFRP Bars in C20 concrete, when the embedded length changes from $5 \mathrm{~d}$ to $10 \mathrm{~d}$, the bond strength decreases by $28.89 \%$; for the $13 \mathrm{~mm}$ diameter GFRP Bars in C40 concrete, when the embedded length changes from $5 \mathrm{~d}$ to $10 \mathrm{~d}$, the bond strength decreases by $14.68 \%$. This is the result of the non-linear distribution of the bond stress along the GFRP bar. The larger the embedded length of GFRP bar in the tests specimen is, the more uneven the bond stress distribution is, the smaller the ratio of the bond strength $\tau_{\mathrm{u}}$ to the maximum bond stress $\tau_{\max }$ is, so the bond strength decreases with the increase of the bond length.

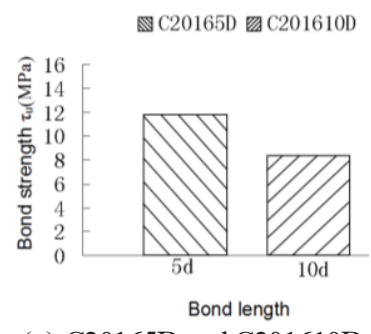

(a) C20165D and C201610D

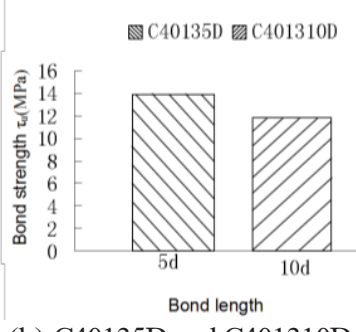

(b) C40135D and C401310D
Fig. 7. Effect of bond length on bond strength.

(3) Failure mode: the comparison of bond strength of GFRP Bars under different failure modes is shown in Fig. 8. It can be seen from Fig. 8 that the bond strength of the specimen with splitting failure is higher than that with pull-out failure. With the increase of bond length, the failure mode changes from pull-out to splitting failure, and the bond stress also increases. This shows that the failure mode has a significant effect on the bond strength.

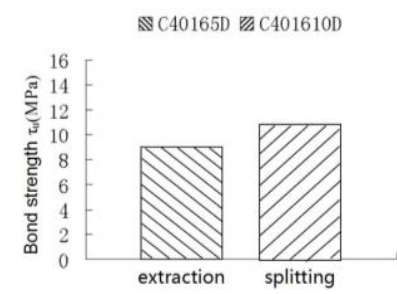

failure mode

(a) C40165D and C401610D $\mathbb{N}$ C30105D $\mathbb{Z}$ C301010D

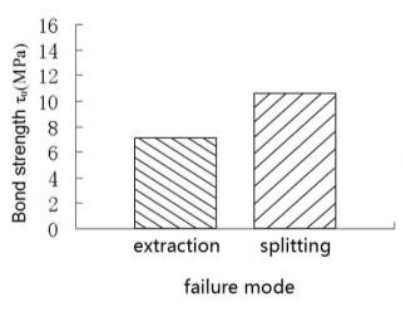

(c) C30105D and C301010D

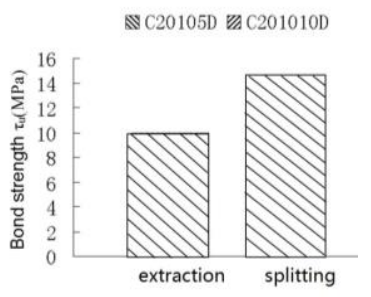

failure mode

(b) C20105D and C201010D $\mathbb{N}$ C30165D $\mathbb{Z}$ C301610D

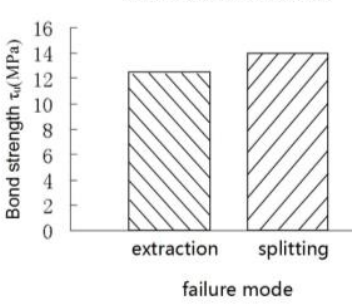

(d) C30165D and C301610D
Fig. 8. Effect of failure mode on bond strength.

\section{Conclusion}

In this paper, a total of 27 pull-out specimens were designed with the parameters of bond length, concrete strength and GFRP bar diameter. The test was carried out and the data of load, slip and reinforcement strain were collected. The main conclusions are as follows:

(1) GFRP Bars are always elastic during the test process, and the stress stage of specimen can be divided 
into microslip stage, linear slip stage, nonlinear slip stage and bond failure stage.

(2) There are three types of failure mode of the specimens: splitting failure, pull-out failure and fracture failure of GFRP bar. When the bond length is $5 \mathrm{~d}$, the failure mode is pull-out; when the bond length is increased to $10 \mathrm{~d}$, the failure modes are pull-out failure and split failure; when the embedded length is $20 \mathrm{~d}$, most of the failure mode is fracture failure of GFRP bar.

(3) With the increase of bond length, the bond strength between GFRP reinforcement and concrete decreases, the bond strength of specimens with splitting failure is higher than that of specimens with pull-out failure. There is no significant correlation between the concrete strength and bond strength.

\section{Acknowledgment}

This work was supported by the National Key Research and Development Program of China(2017YFC0806100) and National Natural Science Foundation of China (51178206).

\section{References}

1. Qi Deqing, Qian Wenjun, Xue Weichen. Progress of studies on durability of FRP bars used in civil engineering $[\mathrm{J}]$. Fiber Reinforced Plastics/Composites, 47(2006):

2. Ye Lieping, Feng Peng. Applications and development of fiber-reinforced polymer in engineering structures[J]. China Civil Engineering Journal, 39, 24(2006)

3. American Concrete Institute (ACI) Committee 440. Guide for the design and construction of concrete reinforced with FRP bars ACI440.IR-15[S] Farmington Hills: American Concrete Institute (2015)

4. Wang xiaolu, Zha xiaoxiong, Zhang xushen. Bond performance of FRP bars and concrete under high temperature condition[J]. Journal of Harbin University of Technology, 45, 8(2013)

5. Amnon Karz, Nela Berman. Modeling the effect of high temperature on the bond of FRP reinforcing bars to concrete [J]. Cement \& Concrete Composites, 22, 433(2000)

6. Abdolkarim Abbasi, Pauli. Hogg. Temperature and environment effects on glass fiber rebar: modulus, strength and interfacial bond strength with concrete[J].Composites: Part B,394(2005)

7. Standard for test method of mechanical properties on ordinary concrete: GB/T 50081-2002[S]. Beijing: China Architecture Building Press, (2003) 